\title{
Oestrogen, testosterone, cytotoxin and cholinesterase inhibitor removal during reclamation of sewage to drinking water
}

\author{
AK Faul'1,2, E Julies', and EJ Pool ${ }^{2 *}$ \\ 'Department of Biological Sciences, University of Namibia, Windhoek, Namibia \\ ${ }^{2}$ Department of Medical Biosciences, University of the Western Cape, Bellville, South Africa
}

\begin{abstract}
Namibia is the driest sub-Saharan country in Africa. Namibia's capital, Windhoek, reclaims sewage water for domestic use at the Goreangab Water Reclamation Plant (GWRP). Risks associated with sewage effluent and reclaimed sewage should be closely monitored; therefore water at the Gammams Sewage Treatment Plant (GSTP) inlet and outlet, as well as reclaimed water from the GWRP, were assayed using selected bioassays. Samples collected were analysed using enzyme-linked immunosorbent-assays and chromogenic tests for steroid hormones, neurotoxicity, cytotoxicity and inflammatory activity. Estradiol level at the sewage treatment inlet was $78 \mathrm{pg} / \mathrm{m} \ell$ and the treated sewage level showed an $83 \%$ to $95 \%$ reduction in this, while after reclamation the level was below detection limit. Estrone concentrations at the sewage treatment inlet ranged from 10 to $161 \mathrm{pg} / \mathrm{m} \ell$. Sewage treatment reduced estrone by between $85 \%$ and $92 \%$. After reclamation the level of estrone was below detection limit. Testosterone ranged between 162 and $405 \mathrm{pg} / \mathrm{m} \ell$ at the sewage plant inlet. Sewage treatment removed $96 \%$ of the initial testosterone. The residual testosterone was effectively removed by processes in GWRP and after reclamation no testosterone was detected in water. Acetylcholinesterase $(\mathrm{AChE})$ inhibition at the sewage treatment inlet was $50 \%$ while it was only $27 \%$ after sewage treatment. After reclamation AChE inhibition was not detected. Only water at the sewage inlet in March and February showed cytotoxicity. High inflammatory activity was detected at the sewage plant inlet. Sewage treatment reduced inflammatory activity by $64 \%$. After reclamation low inflammatory activity was induced. Treated sewage used for reclamation tested positive for most of the biomarkers and can pose a risk to human health. However, reclamation successfully removed these contaminants. Due to the presence of contaminants in the intake water at the reclamation plant, it is essential to routinely monitor the water produced by the reclamation plant for potential residues that can adversely affect human health.
\end{abstract}

Keywords: Endocrine disrupting potential, cytotoxicity, neurotoxicity, inflammatory response, steroid hormones, water quality

\section{INTRODUCTION}

The protection and management of water resources are becoming increasingly important. The growing human population, linked to its resource needs, puts existing water sources under immense pressure due to unsustainable use and effects of various environmental pollutants. Namibia has to take special care of its water sources, since it is the driest sub-Saharan African country, with an average rainfall of $360 \mathrm{~mm}$ per year. More than half of the surface of this country is considered semiarid to hyper-arid. This is further aggravated by extremely high evaporation rates of 3000-3 $500 \mathrm{~mm} / \mathrm{a}$ (Mendelsohn et al., 2009). With a total land surface area of $825000 \mathrm{~km}^{2}$ and just over 2 million inhabitants it is one of the most sparsely populated countries in the world (Mendelsohn et al., 2009). Urbanisation has led to more than $10 \%$ of the country's population settling in the capital city, Windhoek, resulting in an increased demand for clean water.

Windhoek is a relatively small city and home to most of the 250000 people of the Khomas Region (Mendelsohn et al., 2009). The current unofficial estimate for Windhoek's population is more than 300000 inhabitants. In 1969 water shortages

To whom all correspondence should be addressed.

욜 +27 21 959-3535; fax: +27 21 959-3125;

e-mail: epool@uwc.ac.za

Received 29 March 2012; accepted in revised form 8 July 2013. led to the upgrade of the conventional water treatment plant in the vicinity of the Goreangab Dam to a fully functional water reclamation plant, with the purpose of reclaiming the final effluent from the city's Gammams Sewage Treatment Plant (GSTP) (Du Pisani, 2006). The Goreangab Water Reclamation Plant (GWRP) was the first water reclamation plant of its kind in the world, where the final effluent from a sewage water treatment plant was purified, together with water from the Goreangab Dam, for domestic use and human consumption. In full operation it could deliver up to $4300 \mathrm{~m}^{3} /$ day and the reclaimed water was mixed with borehole water before being delivered to the city of Windhoek (Du Pisani, 2006).

Goreangab Dam later became unfit for reclamation due to increasing organic matter input from expansion of the city as well as informal settlements that lie within the catchment area of the dam. As a result only sewage effluent was reclaimed. In subsequent years the water demand increased further and water had to be sourced from further away. The GWRP underwent several upgrades to finally reach a capacity of between 7500 and $8000 \mathrm{~m}^{3} /$ day in 1997 (Du Pisani, 2006; Kirchner and Van Wyk, 2001). By this time the GWRP reached the end of its viable life and a new, larger plant (also called the Goreangab Water Reclamation Plant or new Goreangab Water Reclamation Plant) was built with a capacity of $21000 \mathrm{~m}^{3} /$ day (Lahnsteiner and Lempert, 2007). Currently it has the potential of supplying up to $30 \%$ of the City of Windhoek's water demand, the other $70 \%$ being supplied from the S Von Bach Dam located approximately $60 \mathrm{~km}$ from Windhoek, as well as from about 
50 boreholes tapping into the Windhoek Aquifer. The new GWRP is managed by the Windhoek Goreangab Operating Company (WINGOC). The old GWRP is still used today to produce semi-purified water for irrigation of Windhoek's parks and sport fields.

Using reclaimed sewage water for domestic purposes has the potential of posing various health threats. This includes the presence of endocrine disrupting compounds (EDCs) that may not be eliminated during the purification process or that may result from malfunctioning of the reclamation plant. Endocrine disrupting compounds include various natural and synthetic chemicals and compounds, the most important being natural and synthetic steroidal oestrogens and heavy metals (Bondegaard and Bjerregaard, 2005; Medesani et al., 2004; Rodríguez et al., 2007). These compounds may interfere directly with hormonal systems of various animals by mimicking or antagonising the effects of hormones, altering hormone synthesis and metabolism, and modifying hormone receptor levels (Burkhardt-Holm, 2010). Numerous studies have revealed that aquatic systems and their fauna are often very sensitive to the effects of EDCs (Harries et al., 1997; Porte et al., 2006; Tyler and Routledge, 1998). The effects on endocrine and neural systems of animals, plants, and humans are manifested as adverse effects on growth, development, and reproductive success of individuals and these may eventually affect whole ecosystems (Burkhardt-Holm, 2010; Gronen et al., 1999; Harries et al., 1997; Tyler and Routledge, 1998). The link between EDCs and detrimental effects on the endocrine systems of children, decreased fertility in males, and increased incidence of breast cancer in females has also been suggested by various studies (Burkhardt-Holm, 2010; Rogan and Ragan, 2007). One of the potential sources of EDCs is raw and processed sewage that is released into the environment (Jackson and Sutton, 2008; Swart and Pool, 2007).

One of the most important measures applied to ensure the supply of safe drinking water from the GWRP was to implement and strictly control the separation of industrial effluent from domestic effluent (Du Pisani, 2006). The GSTP feeding the GWRP therefore only receives water from households and small businesses in Windhoek. Furthermore, stringent measures are in place at the GWRP to ensure the highest quality of reclaimed water, and daily testing is performed to ensure that water meets standards provided by the World Health Organization, Rand Water Guidelines (South Africa) and the Namibian Guidelines for Group A Water (Lahnsteiner and Lempert, 2007). If contamination of the water is detected, water supply from the GWRP is immediately stopped. Currently no published literature is available on the efficiency of the removal of EDCs from raw sewage at the GSTP or the efficiency of the GWRP in removing residual EDCs from the GSTP effluent which serves as the inlet for the GWRP. Furthermore, despite a significant amount of research done worldwide on EDCs over the past two decades, no international limits have been set for permissible steroid hormone levels in various water sources. Currently a useful guideline may be predicted-noeffect-concentrations (PNECs) for synthetic oestrogen 17- $\alpha$ ethinylestradiol of $0.1 \mathrm{pg} / \mathrm{m} \ell$, estradiol of $1 \mathrm{pg} / \mathrm{m} \ell$, and estrone of $3-5 \mathrm{pg} / \mathrm{m \ell}$, in freshwater ecosystems (Burkhardt-Holm, 2010). However, the effects of oestrogens vary significantly form species to species and with different environmental conditions (Shin'ichiro et al., 2003). The synergetic effect of different xenobiotic hormones and duration of exposure influence the effects these EDCs may have (Vonier et al., 1996). More research is required to establish safe critical limits. Until these have been
TABLE 1

Rainfall recorded in Windhoek for the particular sampling months

\begin{tabular}{|l|l|c|}
\hline Sampling month & Description & $\begin{array}{c}\text { Average } \\
\text { rainfall }(\mathrm{mm})\end{array}$ \\
\hline March 2010 & Towards end of rain season & 26.5 \\
\hline September 2010 & End of dry season & 11.9 \\
\hline November 2010 & Beginning of rain season & 114 \\
\hline February 2011 & Peak of rain season & 179.3 \\
\hline April 2011 & Towards end of rain season & 161.5 \\
\hline
\end{tabular}

established it is difficult to monitor and implement policies regarding hormone levels at the GWRP.

This study aimed to assess the effectiveness of EDC removal in the GSTP and GWRP. Specific EDCs were quantified in water samples from the GSTP inlet and effluent, as well as from the reclaimed water produced at GWRP. Seven different bioassays consisting of both enzyme-linked immune-sorbent assays (ELISAs) and chromogenic spectrophotometry were used to establish selected steroid hormone levels, immunotoxicity, cytotoxicity and neurotoxicity of the water samples. These bioassays were chosen for their rapid production of reliable results and their endpoints provide an overview of the efficiency of reduction of potential endocrine toxicity of sewage water in the GSTP and GWRP. The results of this study are useful for the establishment of biomarkers for routine monitoring of water reclamation plants.

\section{MATERIALS AND METHODS}

\section{Sample collection}

Water samples were collected on 5 different occasions to include various stages of the wet and dry seasonal cycle (Table 1). This is important, since a higher organic matter load from increasing runoff into the sewage system is expected during the wet season. Windhoek received exceptionally high rainfall for January and February 2011 with the highest monthly rainfall ever recorded for Windhoek occurring in the month of January $(320 \mathrm{~mm})$. The sampling points were (1) the GSTP inlet (raw sewage), (2) the final GSTP maturation pond which also acts as the inlet for the GWRP, (3) the GWRP outlet (Fig. 1) and (4) Friedenau Dam, a suspected unpolluted dam close to Windhoek. Friedenau Dam was included for assay verification purposes.

Water was collected in Schott bottles that had been thoroughly cleaned with soap and then rinsed with tap water followed by distilled water and finally chemically pure acetone. At the sampling point the residue acetone was rinsed from the bottles with the source water. The samples were transported on ice and frozen in the laboratory until solid-phase extraction was performed. For each sample 3 aliquots of $1 \mathrm{ml}$ each were frozen in SureLock tubes for toxicity testing. At all sampling points 1 sample was taken, except during September 2010 when more replicates were taken for assay verification purposes.

\section{Solid-phase extraction}

Frozen samples were left at room temperature to thaw before organics were extracted using DSC-18 solid-phase extraction (SPE) columns (Supelco, Sigma-Aldrich). A modified version of the extraction procedure followed by Pool and Magcwebeba (2009) was used. In short, the column was first washed with 


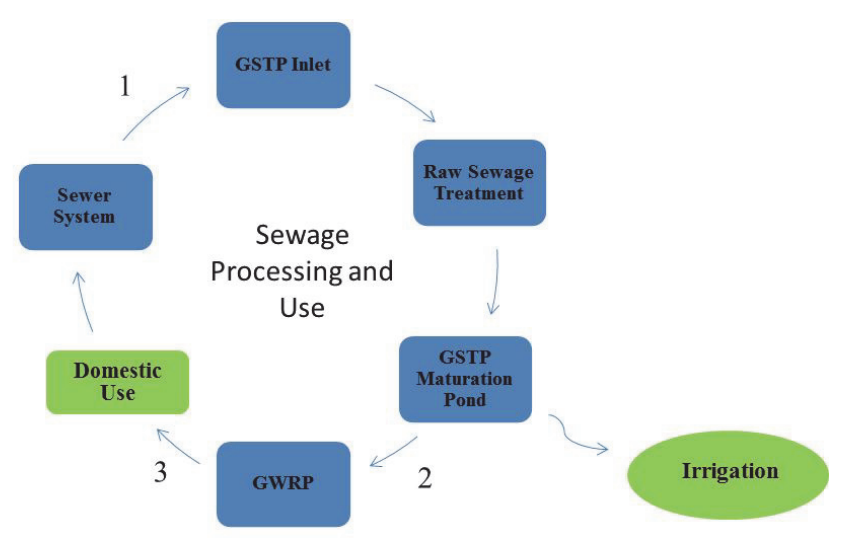

Sampling Points

$1-$ Raw Sewage

2 - Semi-purified sewage/ GWRP inlet

3 - Reclaimed Water

Figure 1

Schematic representation of sewage processing and use in the City of Windhoek at the Gammams Sewage Treatment Plant (GSTP) and the Goreangab Water Reclamation Plant (GWRP)

$2 \mathrm{~m} \ell$ of methanol followed by $2 \mathrm{~m} \ell$ of solvent mixture $(40 \% \mathrm{v} / \mathrm{v}$ hexane, $45 \% \mathrm{v} / \mathrm{v}$ methanol, and $15 \% v / v 2$-propanol). It was then washed with $2 \mathrm{ml}$ of methanol and the column was filled with distilled water, after which the samples were applied. Once the samples had passed through, the columns were dried under vacuum for at least $1 \mathrm{~h}$. The hydrophobic molecules were then eluted from the SPE columns into glass vials by applying two $1 \mathrm{~m} \ell$ volumes of solvent mixture. The eluate was dried under hot air before being reconstituted in dimethyl sulphoxide (DMSO) to a final volume of $0.1 \%$ of the original sample volume.

\section{Steroid hormones}

Steroid hormone levels were determined using Estradiol, Estrone and Testosterone ELISA kits (Sigma, Germany). Assay ranges of the kits are: estradiol 9.7-2 $000 \mathrm{pg} / \mathrm{m} \ell$, estrone 2.21 $1000 \mathrm{pg} / \mathrm{ml}$ and testosterone $83-16000 \mathrm{pg} / \mathrm{ml}$. For estradiol and estrone a 100 -fold dilution, and for testosterone a 50 -fold dilution of the extracts were made using diluted wash solution. All samples were applied to the ELISA microplate in duplicate and the assay procedure of the ELISA kit was followed. In short: standards, controls and samples were applied to the microplate wells. Enzyme conjugate was added and the plates incubated at room temperature. After incubation the plates were washed thoroughly and substrate solution was added. After a short incubation period stop solution was added and absorbance was measured at $450 \mathrm{~nm}$.

Inter- and intra-assay variation of the steroid hormone ELISAs is minimal (Swart and Pool 2007) and therefore eliminates the need for expensive replication of samples. A once-off estradiol verification assay was performed using 3 replicates of each sample taken during September 2010, to determine intra-sample variation. To determine inter-sample variation 15 replicates of 1 sample from the GSTP inlet were analysed.

\section{Blood collection}

Blood was collected at the University Health Centre from a healthy male volunteer that was not on any medication for the 3-month period prior to collection. Blood was collected in sterile heparin vacutainer tubes (Lasec, South Africa) and stored at room temperature. Blood samples were used for experiments within $18 \mathrm{~h}$ of collection.

\section{Neurotoxicity}

Water samples were screened for general neurotoxicity using an acetylcholinesterase inhibition assay. $6 \mu \ell$ of the water extracts was diluted with $54 \mu \ell$ of $0.1 \mathrm{M}$ phosphate buffer. As positive control, $6 \mu \ell$ of $1 \mathrm{nM}$ chloropyrifos in $6 \mu \ell \mathrm{DMSO}$, was used. The negative control consisted of $6 \mu \ell$ DMSO. Both positive and negative controls were diluted to $60 \mu \ell$ with $0.1 \mathrm{M}$ phosphate buffer. The positive control was also used to construct a $4 \mathrm{x}$ dilution range. An acetylcholinesterase extract was prepared by mixing heparinised human blood, distilled water and $0.1 \mathrm{M}$ phosphate buffer (in a ratio of 3:20:97). $25 \mu \ell$ of each sample was added in duplicate to a storage microplate followed by $25 \mu \ell$ of blood solution. The plate was left to incubate for $2 \mathrm{~h}$ after which $50 \mu \ell$ of substrate was added. The substrate consisted of $100 \mu \ell$ of $0.01 \mathrm{M} 5$,5-dithiobis (2-nitro-benzoic acid) (DTNB) that was pre-mixed with $3 \mathrm{~m} \ell$ of $0.1 \mathrm{M}$ phosphate buffer; $20 \mu \ell$ of $0.075 \mathrm{M}$ acetylthiocholine iodide (ATCI) was then added to the DNTB-phosphate buffer mix. Optical density of each sample was immediately determined at $405 \mathrm{~nm}$ and then every $30 \mathrm{~min}$.

\section{Whole blood culture assays}

All culture assays were performed under sterile conditions. Water from each sample was pipetted into duplicate wells $\left(20 \mu \ell /\right.$ well) of a tissue culture plate (Nunc ${ }^{\mathrm{TM}}$, Denmark). Sterile distilled water was used as a negative control. Heparinised blood ( $5 \mathrm{~m} \ell$ ) was added to $45 \mathrm{m \ell}$ Dulbecco's Modified Eagle's Medium (BioWhitakker) and $200 \mu \ell$ of this mixture was added to each well. The plate was covered and incubated overnight at $37^{\circ} \mathrm{C}$, after which the supernatant was collected for lactate dehydrogenase (LDH), interleukin-6 (IL-6) and interleukin-10 (IL-10) analysis.

\section{Cytotoxicity assays}

Lactate dehydrogenase leakage from damaged cells (i.e cell death) into the plasma was monitored as an indication of cytotoxicity. LDH was measured using a commercially available chromogenic LDH assay kit (Sigma, Germany). Diluted blood $(200 \mu \ell)$ was mixed with $20 \mu \ell$ 10\% Tween 20 detergent (Sigma, Germany) to result in complete lysis of the cells. The lysate was used as a $100 \%$ cytotoxicity control. Whole blood culture supernatants or dilutions of the positive control $(10 \mu \ell /$ well $)$ were transferred into wells of a 96-well plate. LDH substrate was prepared according to the manufacturer's instructions and $200 \mu \ell$ of substrate was added to each well. Optical density was immediately determined at $450 \mathrm{nM}$ and then at intervals of $10 \mathrm{~min}$. Between measurements the plate was incubated in the dark and at room temperature. The LDH concentrations were determined using a standard curve constructed from dilutions of the $100 \%$ cytotoxicity control.

\section{Cytokine assays}

Double antibody sandwich ELISAs (e-Bioscience, Germany) were used to determine IL- 6 and IL-10 concentrations in the whole blood culture supernatants collected. The kit's 
TABLE 2

\begin{tabular}{|l|l|c|c|c|c|}
\hline \multicolumn{6}{|c|}{ Intra- and inter-sample variation for the estradiol ELISA as validation of the steroid hormone ELISAs } \\
\hline & Sample site & $\mathbf{N}$ & $\left.\mathbf{E}_{\mathbf{2}} \mathbf{p g} / \mathbf{m} \boldsymbol{\ell}\right)$ & SD & $\%$ SD \\
\hline \multirow{4}{*}{ Intra-sample variation } & Negative control & 3 & 2.0 & 0.1 & 3.6 \\
\cline { 2 - 6 } & Friedenau Dam & 3 & 2.5 & 0.1 & 3.9 \\
\cline { 2 - 6 } & GSTP maturation pond & 3 & 12.8 & 0.9 & 7.2 \\
\cline { 2 - 6 } & GSTP inlet & 3 & 80.8 & 0.3 & 0.3 \\
\hline Inter-sample variation & GSTP inlet & 6 & 80.2 & 0.6 & 0.8 \\
\hline
\end{tabular}

instructions were used with minor modifications. In brief: Nunc-Immuno microplates (Nunc ${ }^{\mathrm{TM}}$, Denmark) were coated with $50 \mu \ell$ of capture antibody in coating buffer and sealed and incubated overnight at $4^{\circ} \mathrm{C}$. Plates were washed 5 times with wash buffer and blotted dry on absorbent paper. Wells were blocked with $100 \mu \ell$ of $1 \mathrm{x}$ assay diluent for $1 \mathrm{~h}$ at room temperature after which they were washed and blotted dry. A 2-fold dilution range of the standard $(50 \mu \mathrm{l} /$ well $)$ was included on all plates. The culture supernatants were diluted 2 -fold with $1 \mathrm{x}$ assay diluent and $50 \mu \ell$ of each sample was added in duplicate wells of the plate. The plates were covered and left to incubate for $2 \mathrm{~h}$ at room temperature. The plates were washed 5 times and blotted dry. Detection antibody $(50 \mu \mathrm{l} /$ well $)$ diluted in $1 \mathrm{x}$ assay diluent was added to wells after which the plates were sealed and incubated for $1 \mathrm{~h}$ at room temperature. The plates were then washed 5 times, blotted dry, and $50 \mu \ell$ of AvidinHorseradish Peroxidase (Avidin-HRP) was added to each well. The sealed plates were left to incubate for $30 \mathrm{~min}$ at room temperature, after which they were washed 7 times and blotted dry. Then $50 \mu \ell$ of substrate solution was added per well and left to incubate for $15 \mathrm{~min}$, after which $25 \mu \ell$ of stop solution was added. Optical densities were determined at $450 \mathrm{nM}$ and IL- 6 and IL-10 concentrations were determined from standard curves.

\section{RESULTS}

\section{Assay verification}

The detection limit of the estradiol ELISA is between $9.7 \mathrm{pg} / \mathrm{m} \ell$ and $2000 \mathrm{pg} / \mathrm{ml}$. Intra-sample variation is shown for a negative control, Friedenau Dam, the GSTP maturation pond and the GSTP inlet (Table 2). Inter-sample variation is shown for 15 replicates produced from a sample taken at the GSTP inlet.

\section{Steroid hormone concentrations}

The highest concentrations of estradiol were found in the GSTP inlet and the GSTP maturation pond. The maturation pond revealed a significant removal of estradiol during the purification process (Fig. 2). The concentrations of estradiol in the GWRP outlet (the reclaimed water) were below detection limit. The highest estradiol concentrations in the GSTP inlet were recorded for the months of September 2010 and April 2011. Estrone concentrations in the GSTP inlet increased significantly at the start of the rainy season, from below $20 \mathrm{pg} / \mathrm{m} \ell$ to $161 \mathrm{pg} / \mathrm{m} \ell$ in November 2010 (Fig. 3). Subsequent months showed a gradual decrease in estrone levels as the rainy season continued. Significantly reduced estrone concentrations were measured in the GSTP maturation pond with the highest concentrations measured in November 2010 $(19.5 \mathrm{pg} / \mathrm{ml})$. The estrone levels for the GWRP are below detection limit.

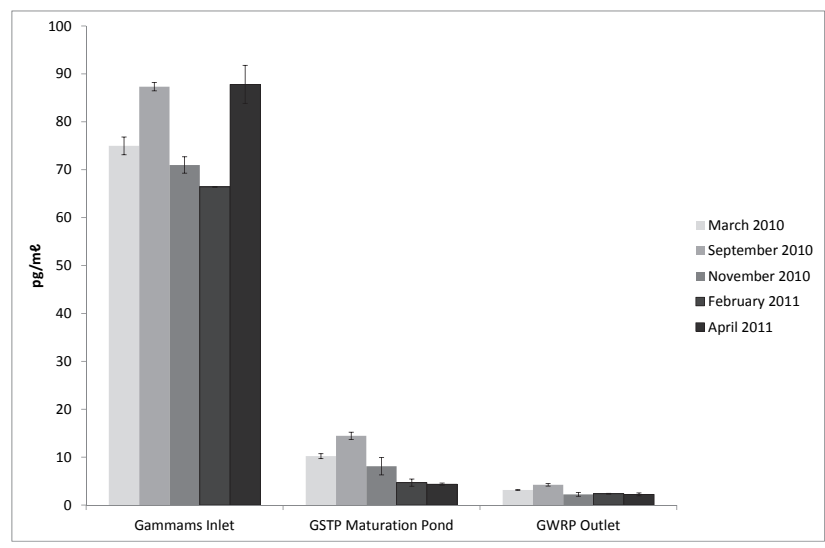

Figure 2

Estradiol concentrations ( $\mathrm{pg} / \mathrm{ml}$ ) for the months March, September, November 2010 and February and April 2011

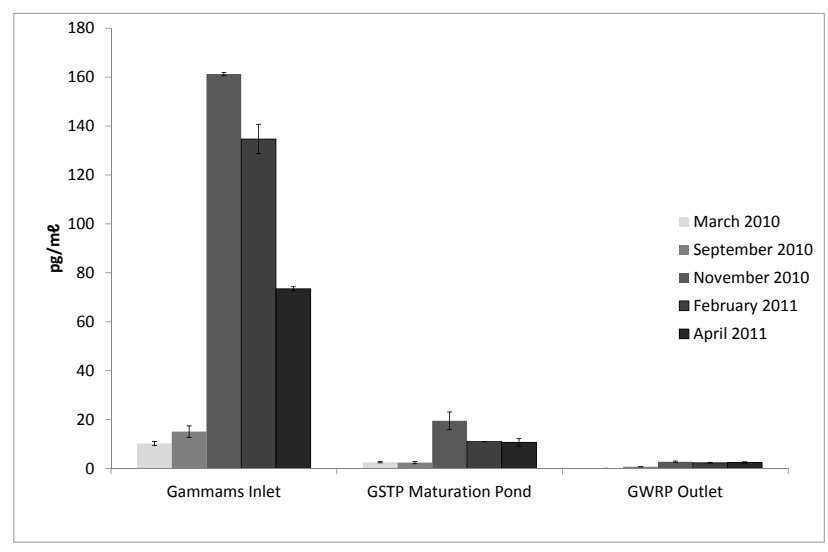

Figure 3

Estrone concentrations ( $\mathrm{pg} / \mathrm{m} \ell$ ) for the months March, September, November 2010 and February 2011 and April 2011

High testosterone levels, ranging from 150 to approx. $400 \mathrm{pg} / \mathrm{m} \ell$, were detected in the GSTP inlet for all of the months sampled (Fig. 4). March 2010 and April 2011 show the lowest levels, of 162 and $159 \mathrm{pg} / \mathrm{m \ell}$, respectively, while the highest value, of $405 \mathrm{pg} / \mathrm{m} \ell$, was detected for November 2010, at the start of the rainy season. Testosterone removal is highly effective during the sewage water treatment process, since testosterone was not detected in any samples from the GSTP maturation pond and GWRP outlet.

\section{Neurotoxicity}

Acetylcholinesterase inhibition is high in the GSTP inlet for all months, except February 2011 when no inhibition is recorded and April 2011 when low inhibition is recorded 


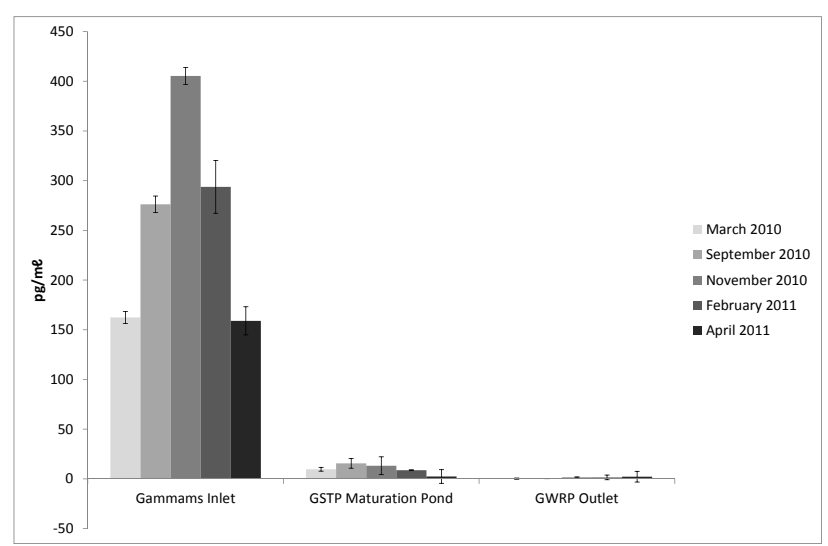

Figure 4

Testosterone concentrations ( $\mathrm{pg} / \mathrm{m} \ell)$ for the months March, September, November 2010 and February 2011 and April 2011.

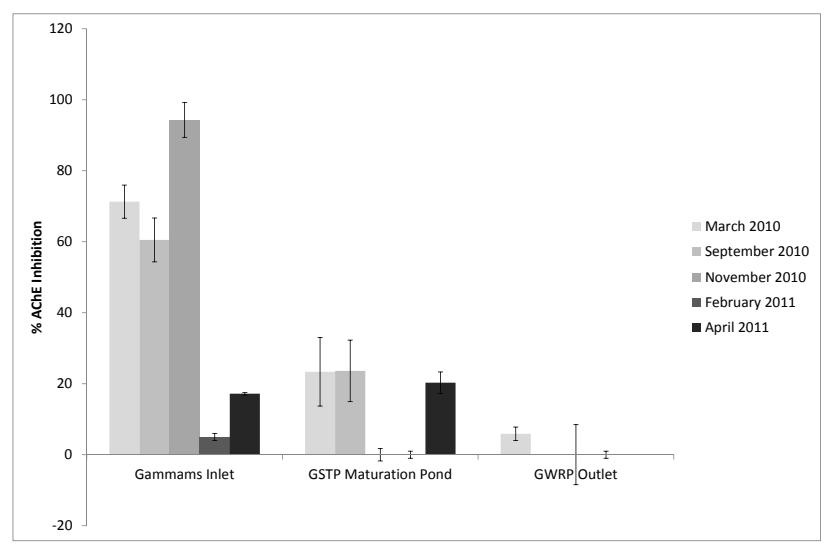

Figure 5

Human blood acetylcholinesterase inhibition by water samples collected at the GSTP inlet, GSTP maturation pond and GWRP outlet. Acetylcholinesterase inhibition is presented as a percentage of the AChE activity of the negative control

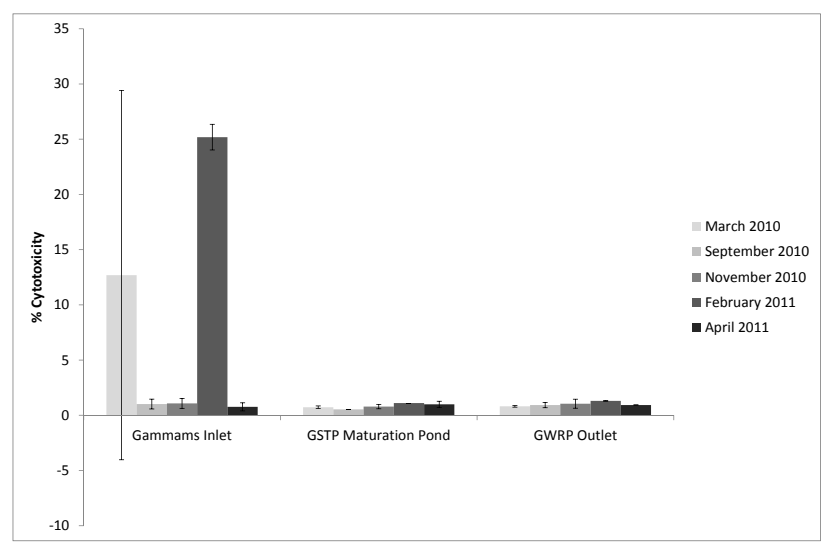

Figure 6

Percentage cytotoxicity of water extracts from the GSTP inlet, GSTP maturation pond and GWRP outlet measured as concentrations of lactate dehydrogenase in supernatants of human blood cultures

(Fig. 5). Highest inhibition is recorded in November when total AChE inhibition is 94\%. The GSTP maturation pond shows $22 \pm 7 \%$ AChE inhibition for March and September 2010 and April 2011. No inhibition was measured for November

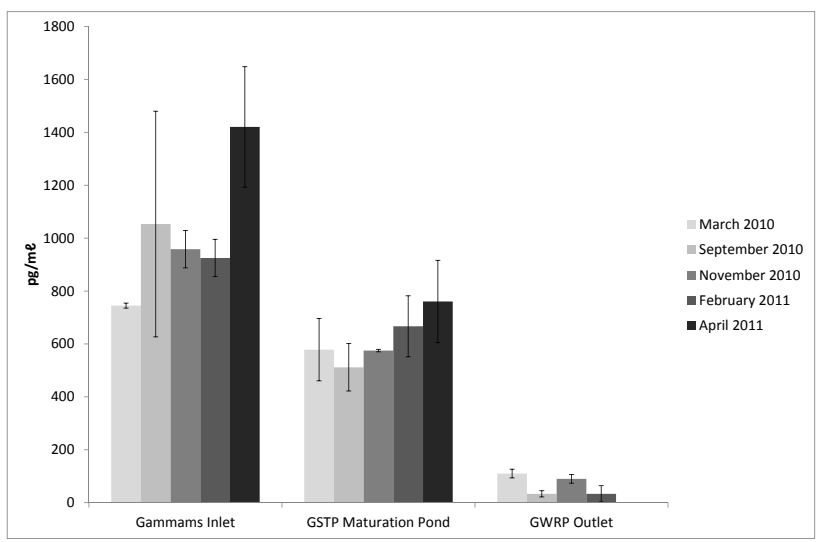

Figure 7

IL-6 concentrations in blood culture supernatants after overnight exposure to the extracts of water from the GSTP inlet, GSTP maturation pond and GWRP outlet

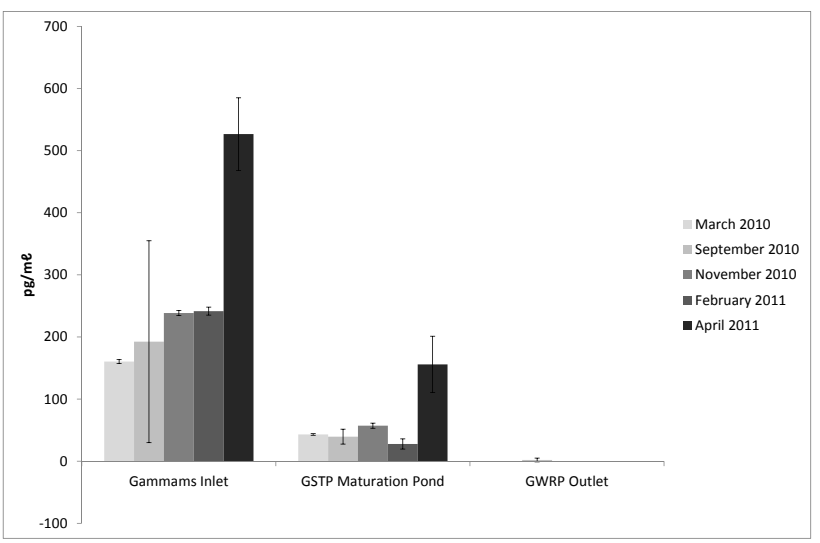

Figure 8

IL-10 concentrations in blood in blood culture supernatants after overnight exposure to the extracts of water from the GSTP inlet, GSTP maturation pond and GWRP outlet

2010 and February 2011. The GWRP outlet shows no AChE inhibition, except for March 2010 when a 6\% AChE inhibition was detected.

\section{Inflammatory activity for cytotoxicity and cytokine analysis}

Cytotoxicity was only detected in the March 2010 (13\%) and February 2011 (25\%) samples of the GSTP inlet (Fig. 6). All other samples for the GSTP inlet as well as the maturation pond and GWRP outlet were negative.

High blood cytokine IL-6 levels were recorded after exposure of whole blood cultures to water extracts collected at the GSTP inlet (Fig. 7). The lowest concentration was recorded in March 2010 (745 pg/m $)$ and the highest in April 2011 (1 421 $\mathrm{pg} / \mathrm{m \ell}$ ). During September and November 2010 and February 2011 concentrations ranged between 900 and $1100 \mathrm{pg} / \mathrm{m \ell}$. Water extracts from the GSTP maturation pond show reduced inflammatory activity with IL-6 levels reducing to between 500 and $800 \mathrm{pg} / \mathrm{m \ell}$ (average $618 \mathrm{pg} / \mathrm{m \ell}$ ). Water collected at the GWRP outlet induced very low IL-6 levels (average $52 \mathrm{pg}$ / $\mathrm{ml}$ ) compared to the GSTP inlet and GSTP maturation pond samples. This translates into a $38 \pm 12 \%$ reduction during sewage treatment. After reclamation only $9 \pm 8 \%$ of the initial IL- 6 inducing activity was detected in the samples. 
IL-10 levels in culture supernatants ranged between 150 and $250 \mathrm{pg} / \mathrm{ml}$ for the months of March, September and November 2010 as well as February 2011 (Fig. 8). During April 2011 a significant increase in IL-10 production was detected in both the GSTP inlet and maturation pond, with the inlet reaching $527 \mathrm{pg} / \mathrm{m} \ell$. Water treatment in GSTP resulted in a significant reduction in IL-10 production. The GWRP outlet tested negative for IL-10 induction.

\section{DISCUSSION}

The GWRP in Windhoek reclaims a significant proportion of treated wastewater to supplement the domestic water supply. Therefore, there are concerns regarding the presence and potential effects of EDCs, although the main concern of the public still remains microbial pollution and algal toxicity. EDCs and their presence in the environment are still not well known to the general Namibian public.

Relatively high levels of steroid hormones are present in the raw sewage entering the GSTP. However, during processing at the GSTP and the GWRP steroid hormones and neurotoxic, cytotoxic and immunotoxic chemicals present in raw sewage are effectively removed. Endocrine disrupting chemicals can be removed through various steps in the sewage treatment process. Biodegradation and sorption by activated sludge seems to be the most efficient and often used step for the removal of hormones, especially estradiol and testosterone (Janex-Habibi et al., 2009; Leusch et al., 2006). However, for other EDCs its success is reported to be limited (Chang et al., 2009).

Estradiol concentrations in the GSTP inlet were relatively constant throughout the sampling period $(78 \pm 9 \mathrm{pg} / \mathrm{ml})$. This seems to be, on average, a 4 to 5 times higher concentration than for other sewage plants; values of $1.6 \mathrm{pg} / \mathrm{m} \ell$ in Spain (Carballa et al., 2008), $21 \mathrm{pg} / \mathrm{m \ell}$ in Brazil (Ternes et al., 1999), $15 \mathrm{pg} / \mathrm{m \ell}$ in Germany (Ternes et al., 1999), and $15.6 \mathrm{pg} / \mathrm{m \ell}$ in Canada (Servos et al., 2005; Ternes et al., 1999) have been measured. The dissimilarities between measurements might be due to differences in sewage influent properties or differences in the treatment process. Estradiol is efficiently removed in the GSTP, with between $83 \%$ and $95 \%$ removal. This removal efficiency is similar to that in other countries (Carballa et al., 2008; Servos et al., 2005; Ternes et al., 1999). The water that enters the GWRP is that from the GSTP maturation pond, and all remaining estradiol that was detected in the pond was successfully removed at the GWRP. In line with research done by Kolpin et al. (2004) on the dilution effect on organic wastewater contaminants, lower estradiol concentrations during March and November 2010 and February 2011 can be explained by the dilution effect of runoff rainwater, since these samples were collected during or soon after rain events that resulted in increased runoff into the sewage system. In contrast, during September 2010 the long dry winter resulted in a higher concentration of chemicals in the raw sewage. However, the higher estradiol concentration during April 2011 was measured at the end of a long intense rainy season and one would have expected it to be lower as well. The reason for this increase in concentration is not known, but may have been as a result of raw sewage runoff in the catchment. To our knowledge no information on steroidal hormones in storm-water runoff exists.

Estrone presence showed a different pattern compared to estradiol, with much more seasonal variation in the raw sewage. Initial concentrations for post-wet (March 2010) and postdry months (September 2010) were low $(13 \mathrm{pg} / \mathrm{ml})$. This was followed by a 12 -fold increase in estrone (to $161 \mathrm{pg} / \mathrm{ml}$ ) after the first precipitation in November 2010. As the wet season continued the estrone levels decreased to $135 \mathrm{pg} / \mathrm{ml}$ in February and $74 \mathrm{pg} / \mathrm{m \ell}$ in April 2011. These findings suggest high levels of estrone build-up within the catchment of the GSTP during the dry season, and initial high levels due to runoff during the rainy season. The amount of estrone in raw sewage in comparable studies was $40 \mathrm{pg} / \mathrm{m} \ell$ for Brazil, $27 \mathrm{pg} / \mathrm{m} \ell$ for Germany and 49 pg/m $\ell$ for Canada (Ternes et al., 1999). Removal efficiency in Brazil and Canada ranged from $98 \%$ to instances where estrone levels in the effluent were even higher than in the raw sewage (Ternes et al., 1999). In this study, estrone removal in the GSTP was 100\% during March and September 2010 when initial estrone concentrations were low. During the subsequent months, estrone removal was $85 \%$ to $92 \%$ and the remaining estrone in the maturation pond was completely removed in the GWRP. Estradiol is readily oxidised to estrone under aerobic conditions (Ternes et al., 1999) and studies have shown that estrone may, as a result of this, be found in higher concentrations in the final effluent of sewage treatment plants (Chang et al., 2011; Swart and Pool, 2007). This was however not the case in the GSTP where estrone and estradiol concentrations in the effluent were very similar $(9.2 \pm 1.2 \mathrm{pg} / \mathrm{m} \ell$ and $8.4 \pm 4 \mathrm{pg} / \mathrm{m} \ell$, respectively).

Testosterone concentrations were, on average, much higher than those of estradiol and estrone. This is in agreement with the excretion concentrations of the natural steroid hormones by humans and animals (Shore and Shemesh, 2003), and is similar to trends shown by Leusch et al. (2006) for sewage treatment plants in Australia and New Zealand. Similarly to estrone, testosterone also peaked in November 2010 at the start of the rainy season $(405 \mathrm{pg} / \mathrm{ml})$. Overall, testosterone concentrations showed greater variation between the different samples with the lowest concentration, of 162 and $159 \mathrm{pg} / \mathrm{ml}$, occurring at the end of the rainy season (March 2010 and April 2011), probably as a result of dilution. Testosterone levels measured correspond well with those measured by Stalter et al. (2011) in Switzerland and Germany (21 to $400 \mathrm{pg} / \mathrm{ml}$ ), while Chang et al. (2011) observed much lower concentrations $(21-76.7 \mathrm{pg} / \mathrm{ml})$ in China. Measurements at the GSTP are also within the range of testosterone concentrations measured in Australia and New Zealand (Leusch et al., 2006); however the variation in concentrations measured by Leusch et al. (2006) is much more extreme (113$4300 \mathrm{pg} / \mathrm{ml}$ ). Testosterone was almost completely removed in all of the samples after treatment at the GSTP, with only $10 \pm$ $5 \mathrm{pg} / \mathrm{ml}$ remaining. This represents a $96 \%$ removal efficiency of testosterone, which is the same as that observed in China by Chang et al. (2011)

Although the measured steroid hormone concentrations were drastically reduced in the effluent, it may still pose an environmental and health risk. A multitude of studies have shown that the presence of steroid hormones in effluents has adverse effects on wildlife, including, among others, reduced fertility, abnormal development of male and female secondary sex characteristics, alteration in sex ratio, feminisation of males and alteration of behaviour (Sharpe 1998; Tyler and Routledge 1998; Rodríguez et al. 2007; Saaristo et al. 2009). Thus, where effluent is used for irrigation purposes or excess sewage effluent enters rivers or dams it poses health threats to both animals and humans. In Windhoek, excess sewage effluent ends up in the Goreangab Dam, currently used for recreational purposes (no swimming or fishing allowed). In addition, the effluent is reclaimed at the GWRP to supplement Windhoek's domestic water supply. However, EDC removal in the GWRP was $100 \%$ effective. 
Toxicity of raw and treated wastewater has been demonstrated in previous research (Farcy et al., 2011; Gagné et al., 2011; Macova et al., 2011). Persistent organic pollutants (POPs) like polychlorinated biphenyls, organochlorine pesticides, and polycyclic aromatic hydrocarbons are typically responsible for many of the toxic effects of wastewater and are characterised by persistence, resisting chemical and biological degradation; the most effective means of removal seems to be dissolved organic carbon (DOC), powder activated carbon (PAC) and ozonation (Bolong et al., 2009; Katsoyiannis and Samara, 2007a; Stalter et al., 2011). At the GSTP raw sewage showed neurotoxicity, with 50\% inhibition of AChE. It was only in February 2011, at the peak of the rainy season, that no inhibition was detected. This was probably due to the dilution effect of the continued rain in the catchment area. The highest AChE inhibition, of 94\%, was detected in November 2010 after the first rains, when toxins washed in from the city environment. Neurotoxicity was reduced by $73 \%$ during the sewage treatment process and $100 \%$ reduction was achieved at the end of the GWRP. This reduction efficiency corresponds well to the study of Macova et al. (2011) on reclamation plants in Australia. Cytotoxicity was low overall and only recorded in the GSTP inlet for March 2010 and February 2011 (13\% and 25\% respectively). Sewage effluent showed no cytoxicity, and this corresponds to studies elsewhere (Smital et al., 2011). Toxicity testing should, however, be done using a wide array of tests to include toxic chemicals of varying characteristics, and to accurately determine toxicity in a wide range of organisms and under different conditions, as suggested by Dizer et al. (2002).

Pro-inflammatory IL-6 levels were very high in all of the raw sewage samples, indicating high microbial activity or microbial breakdown products (Pool et al., 2000) or high steroid hormone presence, especially estradiol (Ansar Ahmed 2000). The IL- 6 level induced by the March 2011 sample was the lowest, at $745 \mathrm{pg} / \mathrm{ml}$, and for April 2011 the highest, at $1421 \mathrm{pg} / \mathrm{m} \ell$. Average IL-6 levels were $1020 \pm 250 \mathrm{pg} / \mathrm{m} \ell$. High levels are to be expected since it is raw domestic sewage containing faecal bacteria, and the highest IL- 6 production also corresponded with the highest estradiol levels in the GSTP inlet. On average the effluent from the GSTP resulted in 38\% less IL- 6 production, indicating that there is still relatively high microbial activity in the effluent. This may pose health risks where the effluent is used for irrigation purposes or if the reclamation process at the GWRP malfunctions. During this study, the reclaimed water had negligible effects on IL- 6 production. Anti-inflammatory IL-10 production was lower than that of IL- 6 with an average of $272 \pm 146 \mathrm{pg} / \mathrm{ml}$ for the raw sewage. Similar to IL- 6 the production of IL-10 was also the lowest for March 2010 and the highest for April 2011.

From this study it is evident that steroid hormone concentrations and neurotoxicity are higher towards the start of the rainy season, and cytotoxicity and immunotoxicity higher towards the end of the rainy season. Neurotoxicity is commonly caused by many anthropogenic chemicals, such as organophosphates that accumulate in the catchment during the dry season and then reach the plant after the first rains. In contrast, cytotoxicity and immunotoxicity are mostly caused by microorganisms that need time to proliferate in polluted water before reaching levels where adverse effects are exoressed. Since the rivers in the catchment are all seasonal rivers they are dry throughout the winter. With initial rains the water is expected to have relatively low microbial content. However, after longer periods of rain, and with accumulation of stagnant pools, there will be increased microbial activity and therefore increased cyto- and immunotoxicity. This may explain the higher cytotoxicity in March and April and higher immunotoxicity in April.

Results from this study indicated that high rainfall decreases the general quality of influent water to the wastewater treatment plant, since the concentration of hormones such as estrone, estradiol and testosterone increases. The increase in the various hormones does not occur simultaneously. Water quality was worst at the beginning of the rainy season due to increased runoff bringing in all the accumulated pollutants from the streets and buildings. During the last, and more intense, part of the rainy season a dilution effect on sewage, and therefore lower endocrine disrupting potential, exists. This study revealed that the GSTP is not entirely successful in the removal of all EDCs, but achieves relatively good results and compares well with other sewage treatment plants, even when the load on the systems drastically increases, as was the case with the exceptionally high rainfall of the 2010/11 rainy season. It also indicates that remaining EDCs are successfully removed by the GWRP. The results of this study form a baseline for further EDC studies on the City of Windhoek's potable water supply. Total oestrogenic activity and androgenic activity, as well as the bioavailability of EDCs, remain to be investigated. Furthermore, EDC presence in the surface and subterranean water sources of Windhoek's water supply should be determined.

\section{ACKNOWLEDGEMENTS}

The authors would like to thank the Research and Publications Committee of the University of Namibia, the University of the Western Cape, and the National Research Foundation of South Africa for funding and resources for the project. We would also like to thank the Windhoek Municipality and the Windhoek Goreangab Operating Company for access to the water samples.

\section{REFERENCES}

ANSAR AHMED S (2000) The immune system as a potential target for environmental estrogens (endocrine disruptors): A new emerging field. Toxicology 150 191-206.

BOLONG N, ISMAIL AF, SALIM MR and MATSUURA T (2009) A review of the effects of emerging contaminants in wastewater and options for their removal. Desalination 239 229-246.

BONDEGAARD M and BJERREGAARD P (2005) Association between cadmium and calcium uptake and distribution during the moult cycle of female shore crabs, Carcinus maenas: An in vivo study. Aquat. Toxicol. 72 17-28.

BURKHARDT-HOLM P (2010) Endocrine disruptors and water quality: A state-of-the-art review. Water Resour. Dev. 26 (3) 477-493.

CARBALLA M, OMIL F and LEMA JM (2008) Comparison of predicted and measured concentrations of selected pharmaceuticals, fragrances and hormones in Spanish sewage. Chemosphere 72 1118-1123.

CHANG H, CHOO K, LEE, B and CHOI S (2009) The methods of identification, analysis, and removal of endocrine disrupting compounds (EDCs) in water. J Hazardous Mater. 172 1-12.

CHANG H, WAN Y, WU S, FAN Z and HU J (2011) Occurrence of androgens and progestorones in wastewater treatment plants and receiving waters: Comparison to estrogens. Water Res. 45 732-740.

DIZER H, WITTEKINDT E, FISCHER B and HANSEN P-D (2002)

The cytotoxic and genotoxic potential of surface water and wastewater effluents as determined by bioluminescence, $u m u$-assays and selected biomarkers. Chemosphere 46 225-233.

DU PISANI PL (2006) Direct reclamation of potable water at Windhoek's Goreangab reclamation plant. Desalination 188 79-88. 
FARCY E, GAGNÉ F, MARTEL L, FORTIER M, TRÉPANIER S, BROUSSEAU P and FOURNIER M (2011) Short-term physiological effects of a xenobiotic mixture of the freshwater mussel Elliptio complanata exposed to municipal effluents. Environ. Res. 111 1096-1106.

GAGNÉ F, ANDRÉ C, CEJKA P, HAUSLER R and FOURNIER M (2011) Evidence of neuroendocrine disruption in freshwater mussels exposed to municipal wastewaters. Sci. Total Environ. 409 (19) 3711-3718.

GRONEN S, DENSLOW N, MANNING S, BARNES S and BROUWER M (1999) Serum vitellogenin levels and reproductive impairment of male Japanese medaka (Oryzias latipes) exposed to 4-tert-octylphenol. Environ. Health Perspect. 107 (5) 385-390.

HARRIES JE, SHEAHAN DA, JOBLING S, MATTHIESSEN P, NEALL P, SUMPTER JP, TYLOR T and ZAMAN N (1997) Estrogenic activity in five United Kingdom rivers detected by measurement of vitellogenesis in caged male trout. Environ. Toxicol. Chem. 16 (3) 534-542.

JACKSON J and SUTTON R (2008) Sources of endocrine-disrupting chemicals in urban wastewater, Oakland, CA. Sci. Total Environ. 405 153-160.

JANEX-HABIBI ML, HUYARD A, ESPERANZA M, and BRUCHET A (2009) Reduction of endocrine disruptor emissions in the environment: The benefit of wastewater treatment. Water Res. 43 1565-1576.

KATSOYANNIS A and SAMARA C (2007a) The fate of dissolved organic carbon (DOC) in the wastewater treatment process and its importance in the removal of wastewater contaminants. Environ. Sci. Pollut. Res. 14 (5) 284-292.

KATSOYANNIS A and SAMARA C (2007b) Ecotoxicological evaluation of the wastewater treatment process of the sewage treatment plant of Thessaloniki, Greece. J. Hazardous Mater. 141 614-621.

KIRCHNER J and VAN WYK A (2001) An overview of the Windhoek city water supply. In: Christellis G and Struickermeir W (eds.) Groundwater in Namibia: An Explanation of the Hydrogeological Map. Department of Water Affairs/Geological Survey Namibia, Windhoek. 78-80.

KOLPIN DW, SKOPEC M, MEYER MT, FURLONG ET and ZAUGG SD (2004) Urban contribution of pharmaceuticals and other organic wastewater contaminants to streams during differing flow conditions. Sci. Total Environ. 328 119-130.

LAHNSTEINER J and LEMPERT G (2007) Water Management in Windhoek/Namibia. Water Sci.Technol. 55 (1-2) 441-448.

LEUSCH FDL, CHAPMAN HF, VAN DEN HEUVEL MR, TAN BLL, GOONERATNE SR and TREMBLAY LA (2006) Bioassayderived androgenic and estrogenic activity in municipal sewage in Australia and New Zealand. Ecotoxicol. Environ. Saf. 65 403-411.

MACOVA M, TOZE S, HODGERS L, MUELLER JF, BARTKOW M, and ESCHER BI (2011) Bioanalytical tools for the evaluation of organic micropollutants during sewage treatment, water recycling and drinking water generation. Water Res. 45 4238-4247.

MEDESANI DA, LÓPEZ GRECO LS and RODRÍGUEZ EM (2004) Interference of cadmium and copper with the endocrine control of ovarian growth, in the estuarine crab Chasmagnathus granulata. Aquat. Toxicol. 69 165-174

MENDELSOHN J, JARVIS A, ROBERTS C and ROBERTSON T (2009) Atlas of Namibia: A Portrait of its Land and People. Sunbird
Publishers, Cape Town, South Africa.

POOL EJ and MAGCWEBEBA TU (2009) The screening of river water for immunotoxicity using an in vitro whole blood culture assay. Water Air Soil Pollut. 200 25-31.

PORTE C, JANER G, LORUSSO LC, ORTIZ-ZARRAGOITIA MO, CAJARAVILLE MP, FOSSI MC and CANESI L (2006) Endocrine disruptors in marine organisms: Approaches and perspectives. Comp. Biochem. Physiol. Part C 143 303-315.

RODRÍGUEZ EM, MEDESANI DA and FINGERMAN M (2007) Endocrine disruption in crustacean due to pollutants: A review. Comp. Biochem. Physiol. Part A. 146 661-671.

ROGAN WJ and RAGAN NB (2007) Some evidence of effects of environmental chemicals on the endocrine system of children. Int. J. Hyg. Environ. Health 210 659-667.

SAARISTO M, CRAFT JK, LEHTONEN KK, and LINDSTRÖM K (2009) Sand goby (Pomatoschistus minutus) males exposed to an endocrine disrupting chemical fail in nest and mate competition. Horm. Behav. 56 315-321.

SERVOS MR, BENNIE DT, BURNISON BK, JURKOVIC A, MCINNIS R, NEHELI T, SCHNELL A, SETO P, SMYTH SA and TERNES TA (2005) Distribution of estrogens, $17 \beta$-estradiol and estrone, in Canadian municipal wastewater treatment plants. Sci. Total Environ. 336 (1-3) 155-170.

SHARPE RM (1998) Environmental oestrogens and male infertility. Pure Appl. Chem. 70 (9) 1685-1701.

SHIN'ICHIRO K, MAKITO K and KANEKO H (2003) Effects of endocrine active substances in wildlife species: Genetic, biochemical, and physiological factors in variable susceptibility to endocrine disruptors. Pure Appl. Chem. 75 (11-12) 2335-2341.

SHORE LS and SHEMESH M (2003) Naturally produced steroid hormones and their release into the environment Pure Appl. Chem. 75 (11-12) 1859-1871.

SMITAL T, TERZIC S, ZAJA R, SENTA I, PIVCEVIC B, POPOVIC M, MIKAC I, TOLLEFSEN KE, THOMAS KV and AHEL M (2011) Assessment of toxicological profiles of the municipal wastewater effluents using chemical analyses and bioassays. Ecotoxicol. Environ. Saf. 74 (4) 844-851.

STALTER D, MAGDEBURG A, WAGNER M and OEHLMAN J (2011) Ozonation and activated carbon treatment of sewage effluents: Removal of endocrine activity and cytotoxicity. Water Res. 45 1015-1024.

SWART N and POOL EJ (2007) Rapid detection of selected steroid hormones from sewage effluents using an ELISA in the Kuils River water catchment area, South Africa. J. Immunoassay Immunochem. 28 395-408.

TERNES TA, STUMPF M, MUELLER J, HABERER K, WILKEN RD and SERVOS M (1999) Behaviour and occurrence of estrogens in municipal sewage treatment plants - I. Investigations in Germany, Canada and Brazil. Sci. Total Environ. 225 81-90.

TYLER CR and ROUTLEDGE EJ (1998) Oestrogenic effects in fish in English rivers with evidence of their causation. Pure Appl. Chem. 70 (9) 1795-1804.

VONIER PM, CRAIN DA, MCLACHLAN JA, GUILLETTE LJ and ARNOLD SF (1996) Interaction of environmental chemicals with the estrogen and progesterone receptors from the oviduct of the American Alligator. Environ. Health Perspect. 104 1318-1322. 